\title{
Has the Construction of the Free Trade Zone Increased the Enterprise's Total Factor Productivity—Evidence from Generalized Synthetic Control
}

\author{
Chao Zhou ${ }^{1}$ \\ ${ }^{1}$ School of Centural university of Finance and Economics, Beijing, China \\ Correspondence: Chao Zhou, School of Centural university of Finance and Economics, Beijing, China.
}

Received: July 22, 2020

Accepted: August 24, 2020

Available online: August 26, 2020

doi:10.11114/afa.v6i2.4983

URL: https://doi.org/10.11114/afa.v6i2.4983

\begin{abstract}
The Free Trade Zone(FTZ) is a new policy for China to open wider to the outside world. Reducing trade barriers and promoting high-quality enterprise development is an important part of the construction of the FTZ. This article takes the construction of the FTZ based on From 2004 to 2018 as a quasi-natural experiment. The study found that: (1) The policy evaluation results show that after controlling the time and individual effects, the construction of the FTZ plays a significant role in promoting TFP. (2) The construction of the FTZ can promote the improvement of TFP through innovation-driven effects and resource allocation adjustment effects. The analysis shows that patents and the return on assets play an intermediary role between the FTZ and TFP. (3) After considering the time and industry effects, the construction of the FTZ has a significant impact on the TFP growth in state-owned enterprises; the general synthetic control method was used to investigate $11 \mathrm{FTZ}$, and the construction of Shanghai free trade zone has the most significant effect on the promotion of TFP. The main innovation of this article is the establishment of the FTZ has carried out a policy effect evaluation on the promotion effect of TFP, and has conducted a robustness test using the multi-phase DID method. It has a guiding significance for improving the construction of FTZ and promoting the improvement of enterprise TFP.
\end{abstract}

Keywords: Free trade zone, TFP, Generalized synthesis control, Multi-phase DID

\section{Introduction}

Since China's accession to the WTO, Sino-US trade friction has been constant. From 2003 to the end of 2005, the United States unilaterally initiated trade friction, in 2008 the United States broke out of the subprime crisis, this crisis is leading to weak global economic growth, the world economy is in deep adjustment, some countries and regions for their own economic development, began to implement trade protectionism, "anti-globalization" ideology rise quickly. In recent years, international trade has gradually begun to form a new pattern, governments and some international institutions on the international trade system structure and management of the international trade has undergone considerable changes. In order to cope with this situation, the Chinese government began to change the way of China's economic development. Free trade zones(FTZ) came into being in this context, the Shanghai FTZ was established with the approval of the State Council and was officially listed on September 29, 2013; three newly established free trade zones in Guangdong, Tianjin and Fujian were officially listed in April 2015; after Approved by the government, seven free trade zones including Liaoning, Zhejiang, Henan, Hubei, Chongqing, Sichuan and Shaanxi were established and officially listed in March 2017; six free trade zones in Shandong, Jiangsu, Guangxi, Heilongjiang, Hebei and Yunnan were established and officially listed in Agust 2019. China's free trade zone has formed a pattern of $1+3+7+6$. Therefore, the economic effects of the establishment of the FTZ has become a focus of academic research. The main question we are facing is: whether the free trade zone is improved The total factor productivity(TFP) of enterprises? Is there any heterogeneity in the effect of different free trade zones on the total factor productivity due to the different implementation time and specific objectives? What is the mechanism of the effect of the construction of free trade zones on total factor productivity? The answers to these questions are: It is of great significance to strengthen the construction of a free trade zone and promote the increase of TFP, thereby achieving high-quality and healthy development of the Chinese economy. 


\section{Literature Review}

The free trade zone studied in this article is based on the concept of FTZ, that is, a regional special economic zone established in the country according to national laws. Reducing administrative intervention in the sale and purchase of the region, giving various tax incentives such as tariff reductions and exemptions to promote enterprise development. FTZ's advantage is that there is no need for multi-country negotiations, only the country needs to formulate its own policies. The traditional free trade area is the concept of FTA, which is a trade agreement that requires multi-country negotiations to reach. FTA has a high rule-making cost and requires a long-term multi-country Consultation, and finally formulate rules on the basis of international agreements.

In academic circles, there are two diametrically opposed views on the traditional free trade area (FTA), which can be divided into positive and negative views. The positive view is that the free trade area can eliminate some international trade barriers and utilize advanced global resources. At the same time, reducing transaction costs can promote global economic development. The main representatives are Krugman (1993), Venables (2003), Chauffour \& Maur (2011), Feils \& Rahman (2008). These views believe that the FTA can promote economic development among member countries , Increase social welfare and improve the TFP of enterprises. The negative view is that the FTA will increase the imbalance of regional economic development and hinder the flow of resources and trade within and outside the trade zone. It will also widen the wage gap between inside and outside the trade zone. Aggravating the income gap and even distorting trade costs. The main representatives are Polaski (2006), Jenkins and Kuo (2013) and Siroën and Yücer (2014). It can be seen that there are still large academic circles on the economic effects of FTAs Disagreement. Although the above views are based on FTA, there is no doubt that these views can also be used to analyze FTZ, and the following will mainly discuss related research under the concept of FTZ.

\section{(1) Economic effect of FTZ}

In the domestic research on free trade zones, most of the articles are studied from a qualitative perspective. The Expert Group of Shanghai University of International Business and Economics (2013) elaborated on the development background and various policies of Shanghai FTZ. Shuanghua Chen (2014) compared Shanghai and foreign FTZ from the perspective of service trade development. Aizhen Chen and Zhibiao Liu ( (2014) believe that the establishment of the Shanghai FTZ can optimize resource allocation and promote economic growth. Yujiang Bi, Haiyan Tang and Desheng Yin (2014) proposed how to promote China's service trade through FTZ. Qi Chen and Wei Liu (2014) believe that the establishment of the Shanghai FTZ has both positive and negative effects. The FTZ can promote the effective allocation of resources, and enjoy institutional dividends;but the FTZ may attract resources from other regions, and it has a crowding-out effect on other regions, which is not conducive to coordinated and balanced economic development and even unfavorable overall economic growth. Xiangdong Yang (2014) believes that Shanghai's "pre-entry national treatment" and "negative list" models of the FTZ can promote more fair competition among enterprises by reducing taxes and transaction costs, thereby promoting economic development within the FTZ. Bin Sheng (2017) conducted an evaluation of the results of the established free trade zone from many different perspectives, and put forward policy recommendations on how to develop the free trade zone better.

In recent years, with the continuation of the implementation of the FTZ, some scholars have begun to study the economic effect of the FTZ from a quantitative perspective. Na Tan(2015) found that Shanghai's industrial added value and total imports and exports increased by 2.69 and 6.73 percentage points. Houjun Xiang and Kang He (2016) used psm-did and synthetic control methods to believe that the establishment of the Shanghai FTZ has a significant impact on capital flows. Lihui Wng(2017) found that free trade zones have a positive economic effect on economic growth. Binglian Liu and Cheng $\operatorname{Lv}(2018)$ analyzed the economic effects of four free trade zones in Shanghai, Tianjin, Guangdong and Fujian using synthetic control methods. It is believed that the establishment of the free trade zone can have a significant degree of positive impact on the import and export trade of goods, economic growth, and investment in fixed assets, and the economic impact of different free trade zones has obvious characteristics of differentiation. Binglian Liu and Yue Wang (2018) Using the synthetic control method to construct a "counterfact" sample, believe that the establishment of the Shanghai Free Trade Zone can significantly promote the improvement of Shanghai's innovation level. Ruidong Han (2019) used synthetic control to study the impact of the establishment of the Shanghai, Tianjin, Guangdong and Fujian Free Trade Zones on cross-border capital flows, and concluded that the impact of FTZ on ODIs was greater than FDI. Chao Zhou(2020) used Multi-phase DID to study the impact of the establishment of FTZS on TFP, and concluded that the construction of FTZS has a postive effect on TFP.

In view of the above reviews, most of the economic effects of FTZs are analyzed using provincial-level macro data. Quantitative analysis methods mostly use synthetic control methods or PSM-DID methods, and existing quantitative analysis has obvious defects. (1)The scope of the FTZ is unclear. Taking Shanghai as an example, the area of the Shanghai free trade zone is only 28.78 square kilometers, accounting for only 1/226 of the total area of Shanghai, and the existing quantitative research literature on the Shanghai FTZ is basically the overall data of Shanghai, and the scope 
of the free trade zone is artificially expanded during the study. For the study of the Fujian and Guangzhou free trade zones, the data of the entire province is used, but the scope of the free trade zone only includes Fujian and Guangzhou. Part of the prefecture-level cities. (2) Existing studies using synthetic control, although there are more control groups on the surface, but few are often retained in the choice of fitting, such as studying the synthesis of the Shanghai Free Trade Zone. Most studies in Shanghai used only Beijing, Jiangsu, and Zhejiang data, which led to the collection of data from multiple provinces, but most of the control groups were excluded when calling the control group data to fit the experimental group. (3) Most of the empirical analysis articles are mainly on the study of Shanghai, and some scholars have also studied Tianjin, Guangzhou, and Fujian FTZS, but no articles have yet included the newly established 7 free trade zones into the analysis to study 11 FTZS policies at the same time. (4) Existing researches use macro data to analyze the policy effects of FTZS, and have not found articles that analyzing from micro data. One of the shortcomings of using macro data is that it is difficult to solve endogenous problems. In addition, it is difficult to map the macro data to the scope of the FTZS. The research in this paper will try to solve the defects of the existing research, using the micro data of the Chinese listed companies. The economic effects of FTZ policies are quantitatively analyzed using the ideas of multi-phase DID, such as the generalized synthetic control method proposed by Yiqing Xu (2017) and Thorsten Beck (2010).

This article uses the data of A-share listed companies to analyze the impact of FTZ construction on TFP, enabling a more detailed analysis to avoid the limitations of using provincial data in Guangzhou and Fujian free trade zones. The time difference in the implementation of the policy, the study of the cause and effect relationship of the free trade zone policy has the following difficulties. (1) The construction of the FTZ and the improvement of TFP have mutual causal problems, and the construction of the FTZ can promote the improvement of TFP; However, it is because of the trade convenience in the place where the FTZ is established, it has a high TFP, so the FTZ is piloted in this area. (2) There are certain selective errors, and the construction of the free trade zone is through the State Council. Established after a comprehensive evaluation by the local government, these areas have their own uniqueness, and it is difficult to choose a suitable control group. (3) The construction of different FTZS is not at the same time, the traditional simple DID is no longer suitable to analysis the TFP improvement by FTZS.

The writing of this article will mainly focus on the following points: (1) To construct the theoretical mechanism of the FTZ to improve the productivity of all factors, and put forward the corresponding research hypothesis; (2) The theoretical deduction, variables and data description of the estimation method; (3) Whether the construction of the FTZ promotes TFP evaluation and the use of multi-phase DID method to test the robustness; (4)The theoretical factor of the factor strain on the construction of the FTZ ;(5) To further analyze the heterogeneity of FTZ policy, and finally, put forward the conclusion and policy recommendations on the impact of FTZ construction on TFP.

\section{Theoretical Mechanism and Research Hypothesis}

The purpose of the construction of the FTZ is to deal with the new normal of economic growth and promote supply-side structural reforms by further opening up to the outside world. The construction of the FTZ can be piloted to study whether the FTZ can effectively promote local economic development and achieve simultaneous improvement of economic growth rate and quality of economic growth. Foreign Enterprises in the FTZ can enjoy tax incentives and national treatment. Free flow of capital and fair competition can come true in the FTZ. The impact of FTZ construction on TFP is achieved mainly by the following two effects: (1) Innovation-driven effect, according to the Douglas production function and the Solo model, in addition to labor and capital, technological progress can promote output growth, and play a key role. Through technological innovation, enterprises can bring higher productivity, thus promoting the promotion of TFP. (2) Resource allocation effect, more reasonable resource allocation will certainly require enterprises to have a stronger management capacity, but also need to provide enterprises with a more free competitive environment.Enterprise's management ability and relaxed market environment will improve the enterprise's TFP. The construction of the FTZ eliminates trade barriers, lets the market play a greater role in the allocation of resources, the market will have a higher efficiency of resource allocation, and promote the improvement of FTZ'S TFP.

(I)The construction of FTZS promotes TFP improvement through innovation-driven effects.

According to endogenous growth theory, knowledge and technology play an important role in promoting economic growth, and innovation can drive economic growth. The establishment of the FTZ has enabled enterprises to face a freer market and more competition, and also pay more attention to corporate innovation and intellectual property protection. The FTZ promotes TFP improvement through innovation mainly through the following channels: (1) The construction of the FTZ is a system innovation, Youwen Zhang (2014) believes that the construction of the FTZ can accelerate the innovation of the financial system and help high-tech enterprises to finance. (2) The high openness of the FTZ enables enterprises to face a more free market environment and lower transaction costs when obtaining FDI and making ODI investments. Of course, enterprises in this highly open and competitive market environment to survive, we must continue to carry out technological innovation, improve their competitiveness. (3) The FTZ policy will also attract 
high-quality talents, Binglian Liu and Qi Wang (2018) believe that the FTZ can make the region's knowledge and technology more frequent collision, the resulting knowledge spillover effect will promote innovation to a higher level. To sum up, the construction of FTZ can promote the level of innovation, the level of innovation in enterprises will improve the TFP. Based on the above analysis, the following research hypothesis is proposed in this paper:

H1: The level of innovation plays an intermediary role between the construction of a FTZ and the improvement of TFP.The construction of a FTZ can have a positive impact on TFP through innovation-driven effects.

( II )The construction of FTZS improve the enterprise's TFP through the resource allocation effect

The purpose of the construction of the FTZ is to reduce trade barriers and exclude some enterprises that are not conducive to the development of the FTZ through the negative list. This can not only better play the role of the market in the allocation of resources, but also use government intervention to exclude obvious impacts on regional development. The FTZs improve TFP mainly through the following channels: (1) Yibing Ding et al. (2014) believe that the FTZ can optimize the allocation of funds for enterprises, reduce the financing cost and difficulty of financing, and ease the financing constraints of enterprises, enhance the R\&D investment and innovation capabilities of enterprises, help to improve the TFP. (2) Qingyong Liu (2017) believes that the construction of FTZS can alleviate the problem of enterprise information asymmetry and promote the information communication and exchange between enterprise.The optimized alloction of information resourses can improve the enterprises's TFP.(3) Chengfeng Zhuo et al. (2018) believe that the construction of FTZS can promote the flow of production factors. The cost of acquiring advanced technology can be reduced, which can improve the overall management level of the enterprise and improve the enterprise TFP. Based on the above analysis, this article proposes the following hypothesis:

H2: The enterprises in the FTZ have a higher resource allocation capability.The construction of the FTZ can improve the enterprise TFP through the adjustment effect of resource allocation.

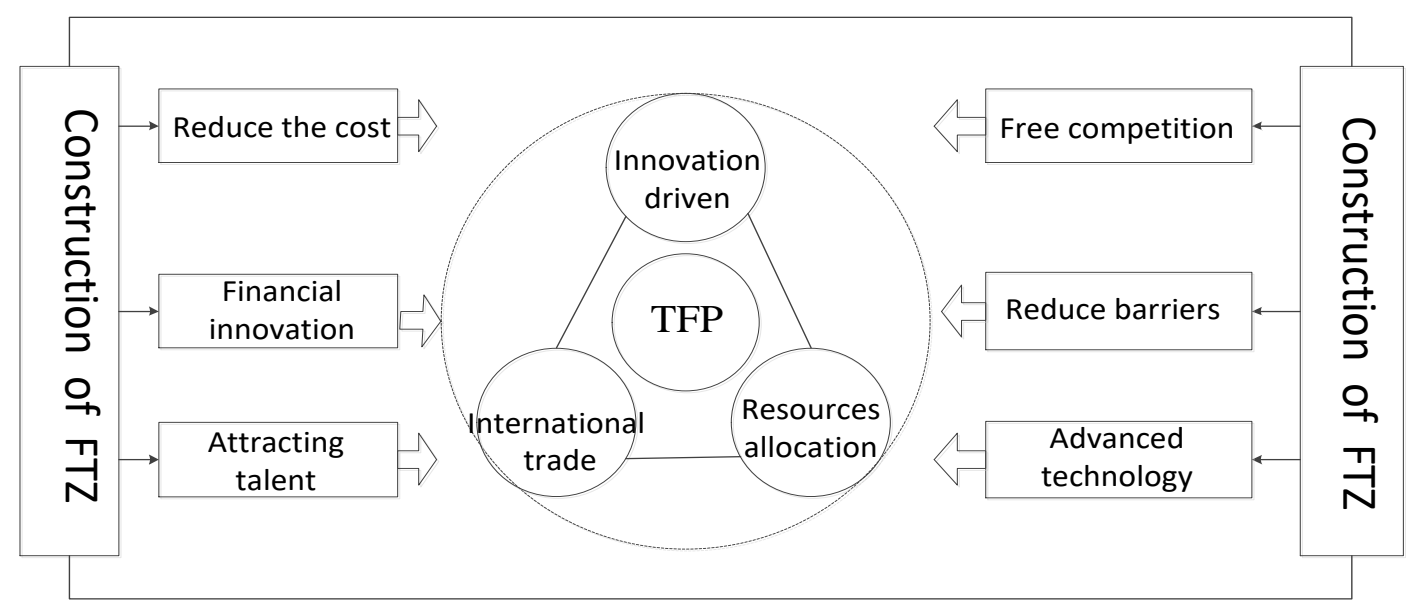

Figure 1. Analysis of the impact mechanism of the FTZ hypothesis on TFP

\section{Estimation Methods, Variables and Data}

(I) Estimation methods

\section{Selection of the scope of the FTZ}

This article selects 11 free trade zones in Shanghai, Tianjin, Guangdong, Fujian, Sichuan, Liaoning, Zhejiang, Henan, Hubei, Shaanxi, and Chongqing as research objects. An important difference between this article and existing research is that it narrows the scope of free trade zones. The selection criteria for the scope of the FTZ is shown in Table 1 below. In order to ensure that there are sufficient samples of the FTZ and a comprehensive examination of the policy effects of the FTZ, eleven FTZS that already having corresponding financial data of the enterprise are included in the analysis. 
Table 1. Selection of the scope of the free trade zone

\begin{tabular}{|c|c|c|c|}
\hline FTZ & Official listing time & Free Trade Zone & $\begin{array}{c}\text { The scope of theFTZ selected in } \\
\text { this article }\end{array}$ \\
\hline Shanghai & September 2013 & $\begin{array}{c}\text { Shanghai Waigaoqiao Bonded Zone, } \\
\text { Waigaoqiao Bonded Logistics Park, } \\
\text { Yangshan Bonded Port Zone and Shanghai } \\
\text { Pudong Airport Comprehensive Bonded } \\
\text { Zone }\end{array}$ & $\begin{array}{l}\text { Pudong New District or } \\
\text { registered address is indicated as } \\
\text { a free trade zone }\end{array}$ \\
\hline Tianjin & April 2015 & $\begin{array}{c}\text { Tianjin Port East Xinjiang Area, Tianjin } \\
\text { Airport Area, Central Business Area }\end{array}$ & $\begin{array}{l}\text { Binhai New Area, Ninghe } \\
\text { District, Dongli District or the } \\
\text { registered address indicates free } \\
\text { trade zone }\end{array}$ \\
\hline Guangdong & April 2015 & Fuzhou area, Xiamen area, Pingtan area & Fuzhou, Xiamen \\
\hline Fujian & April 2015 & $\begin{array}{l}\text { Guangzhou Nansha New Area, Shenzhen } \\
\text { Qianhai Shekou Area, Zhuhai Hengqin New } \\
\text { Area }\end{array}$ & Guangzhou, Shenzhen, Zhuhai \\
\hline Sichuan & March 2017 & $\begin{array}{l}\text { Chengdu Tianfu New District Area, } \\
\text { Chengdu Qingbaijiang Railway Port Area, } \\
\text { Southern Sichuan Port Area }\end{array}$ & Chengdu, Luzhou \\
\hline Liaoning & March 2017 & Shenyang area, Dalian area, Yingkou area & Shenyang, Dalian, Yingkou \\
\hline Zhejiang & March 2017 & $\begin{array}{l}\text { Zhoushan Islands District, Zhoushan Island } \\
\text { Northern District, Zhoushan Island Southern } \\
\text { District }\end{array}$ & Zhoushan \\
\hline Henan & March 2017 & $\begin{array}{l}\text { Zhengzhou area, Kaifeng area, Luoyang } \\
\text { area }\end{array}$ & Zhengzhou, Kaifeng, Luoyang \\
\hline Hubei & March 2017 & Wuhan area, Xiangyang area, Yichang area & Wuhan, Xiangyang, Yichang \\
\hline Shanxi & March 2017 & $\begin{array}{l}\text { Central Area, Yangling Demonstration Area, } \\
\text { Xi'an International Port Area, Xixian New } \\
\text { Area }\end{array}$ & Xi'an, Xianyang \\
\hline Chongqing & March 2017 & $\begin{array}{l}\text { Liangjiang Area, Xiyong Area, Guoyuan } \\
\text { Port Area }\end{array}$ & $\begin{array}{l}\text { Yubei District, Jiangbei District, } \\
\text { Beibei District, Shapingba } \\
\text { District }\end{array}$ \\
\hline
\end{tabular}

Source: According to the official website of the respective trade zone

\section{Introduction of generalized synthetic control method}

In order to overcome the shortcomings of the parallel difference hypothesis required by the double difference method, Abadie \& Cardeazabal (2003) and Abadie (2010) proposed the synthetic control method. If the synthetic control method is used to analyze the data of eleven FTZS at the macro level. However, if it is micro-enterprise data, there are hundreds of companies in eleven FTZS .If each FTZ goes to fitting analysis and will generate a huge workload. It is not conducive to comparative analysis. This article cited Yiqing Xu (2017).The analysis of the FTZ by the generalized synthetic control method can overcome some of the shortcomings of the traditional synthetic control method. Yiqing Xu (2017) Using this method to study the impact of the EDR method on voter turnout in the United States, this article refers to its research method to examine the impact of the construction of FTZS on TFP.

The generalized synthetic control method combines the synthetic control method and the linear fixed-effect model in a simple framework, and the DID model is only a special feature. It first estimates the fixed-effect model of the control 
group data to obtain a fixed number Latent factors. And then linearly project the processing results into the space spanned by these factors, estimating the factor load of each processing unit. Infering the counterfactuals of the processing based on the estimated factors and factor loads. The main contribution of this method is to use latent factors Method to solve the causal inference problem and provide an effective, simulation-based uncertainty estimate under reasonable assumptions. In simple terms, this method is a re-weighting scheme for the synthetic control method, which has three advantages: (1) There is no need to find the matching control group of each experimental group one by one like the synthetic control method.This method only needs to use the fixed-effect model to estimate once, and it can find the counterfactual in one run. (2) There is no need to discard any from the control group. Observation results can use reasonable assumptions to provide effective judgment under the guidance of model data parameters, and can obtain more information from the control group.As long as the model is set correctly, it will be more effective than the synthetic control method. (3) The method is also embedded with the cross-validation scheme, the number of factors in the fixed-effect model will be automatically selected, making it easy to implement.

Of course, the generalized synthetic control method also has its own shortcomings :(1) It requires more periods of data before the implementation of the policy. When the data before the implementation of the policy is not enough, it may produce accidental parameters that affect the evaluation of the effect of policy implementation. (2) Compared with the synthetic control method, it requires more reasonable modeling assumptions. If the experimental group and the control group have no real common influencing factors, they may not constitute a synthetic control unit at all. It is based on the model to fit the counterfactual group, If this method alone may lead to erroneous conclusions, it becomes very important to carry out various tests after using this method.

3. Theoretical derivation of estimation methods

Suppose $T F P_{i t}$ is the TFP of enterprise $\mathrm{i}$ at time t. Let $\mathrm{T}$ and $\mathrm{C}$ represent the experimental group and control group, respectively. Then the total number of enterprises is $N=N_{t r}+N_{c o}, N_{t r}$ with $N_{c o}$ represent the number of enterprises in the experimental group and the control group, respectively. Suppose the data has z periods, $Z_{0 i}$ is the period of the experiment group enterprise $\mathrm{i}$ before the implementation of the free trade zone policy, $Z_{0 i}+1$ began to implement the free trade zone policy. The number of periods for implementing the policy is $q_{i}=Z-Z_{0 i}$. The data of the control group has never implemented the FTZ policy during the entire sample period. For the convenience of using symbols, it is assumed that all the experimental group companies implement the FTZ policy at the same time $Z_{0 i}=Z_{0}, q_{i}=q$. It is also easy to deduce that the FTZ is not implemented at the same time. The generalized synthetic control method must satisfy five basic assumptions.

1. Five assumptions required by synthetic control

Assumption 1: TFP is derived from a linear model, the equation is as follows:

$$
T F P_{\mathrm{it}}=\delta_{\mathrm{it}} D_{\mathrm{it}}+X_{\mathrm{it}}^{\prime} \beta+\lambda_{\mathrm{i}}^{\prime} \mathrm{f}_{\mathrm{t}}+\varepsilon_{\mathrm{it}}
$$

If the enterprise $\mathrm{i}$ has started to implement the policy at time $\mathrm{t}$, then $\mathrm{D}_{i t}$ equal to 1 , otherwise equal to $0 . \delta_{i t}$ is the heterogeneous treatment effect of enterprise $\mathrm{i}$ at time $\mathrm{t}, \mathrm{X}_{i t}$ is an observed one $\mathrm{k} \times 1$ Covariate, $\beta$ is $\mathrm{k} \times 1$ unknown parameters, $\mathrm{f}_{t}$ is an unobserved common factor (such as individual regional effects), is $\mathrm{r} \times 1$ vector, $\lambda_{i} i$ s an unknown factor load, a vector of $\mathrm{r} \times 1, \varepsilon_{i t}$ is a random disturbance term. Hypothesis 1 requires that the experimental group and the control group be affected by the same group of factors, and the number of factors is fixed during the observation period, and no structural interruption can be generated.

In order to formalize the causal conceptual relationship, we use the potential causal framework proposed by Neyman (1923), Rubin (1974), and Holland (1986) for causal inference.TFP $i t(0)$ with $T F P_{i t}(1)$ represent the TFP that did not implement the FTZ policy and the FTZ policy at time t. Then the effect of implementing the FTZ policy is $T F P_{i t}(1)-$ $T F P_{i t}(0)$. According to equation (1), we can get

$$
\begin{gathered}
T F P_{\mathrm{it}}(1)=\delta_{\mathrm{it}}+X_{\mathrm{it}}^{\prime} \beta+\lambda_{\mathrm{i}}^{\prime} \mathrm{f}_{\mathrm{t}}+\varepsilon_{\mathrm{it}} \\
T F P_{\mathrm{it}}(0)=X_{\mathrm{it}}^{\prime} \beta+\lambda_{\mathrm{i}}^{\prime} \mathrm{f}_{\mathrm{t}}+\varepsilon_{\mathrm{it}}
\end{gathered}
$$

According to (2) and (3), we can get $T F P_{i t}(1)-T F P_{i t}(0)=\delta_{i t}$, which is the value that this article is most concerned about. We can rewrite the tfp of each enterprise as:

$$
T F P_{\mathrm{i}}=D_{\mathrm{i}} \circ \delta_{i}+\mathrm{X}_{\mathrm{i}} \beta+\mathrm{F} \lambda_{\mathrm{i}}+\varepsilon_{\mathrm{i}}, \quad \mathrm{i} \in 1,2, \ldots N_{c o}, N_{c o}+1, \ldots N
$$


Among them $T F P_{i}=\left[T F P_{i 1}, T F P_{i 2}, \ldots, T F P_{i Z}\right] ; D_{i}=\left[D_{i 1}, D_{i 2}, \ldots, D_{i Z}\right] ; \delta_{i}=\left[\delta_{i 1}, \delta_{i 2}, \ldots, \delta_{i Z}\right]$. While symbol" 。" represents point-by-point multiplication. $\varepsilon_{i}$ is $\mathrm{z} \times 1$ vector, $\mathrm{X}_{i}$ is $\mathrm{z} \times \mathrm{k}$ vector, and $\mathrm{f}$ is $\mathrm{z} \times \mathrm{r}$ vector.

1 to $N_{c o}$ represents the control group enterprise, then $N_{c o}+1$ to $\mathrm{n}$ represent the experimental group enterprises. The tfp of the control group enterprises can be expressed asTFP $P_{i}=X_{i} \beta+F \lambda_{i}+\varepsilon_{i}, i \in 1,2, \ldots, N_{c o}$. Adding all the control group enterprises together:

$$
\boldsymbol{T F P} \boldsymbol{P}_{c o}=X_{c o} \beta+F \Lambda_{c o}^{\prime}+\varepsilon_{c o}
$$

Among them, $\mathrm{TFP}_{C O}=\left[T F P_{1}, T F P_{2}, \ldots, T F P_{N_{c o}}\right]$ 和 $\varepsilon_{c o}=\left[\varepsilon_{1}, \varepsilon_{2}, \ldots, \varepsilon_{c o}\right]$ AllZ $\times N_{c o}$ dimension vector. $X_{c o}$ YesZ $\times N_{c o} \times$ $p$ dimension vector, $\Lambda_{c o}$ But $N_{c o} \times r$ dimension vector. Therefore $X_{c o} \beta$ withF $\wedge_{c o}^{\prime}$ Should beZ $\times N_{c o}$ dimension vector. $\beta$ 、F、 $\Lambda_{c o}$, need more constraints. Refering to Bai $(2003,2009)$, we add two constraints. (1) All factors are standardized; (2) All factors are orthogonal to each other, such as $F^{\prime} F / Z=\mathrm{I}_{r}, \Lambda_{c o}^{\prime} \Lambda_{c o}=$ diagonal. It is assumed here that the dimension of $r$ is known, and the subsequent part will use an automatic crossover procedure to select $r$. The purpose of this article is to calculate how the FTZ policy will affect TFP. That is, the formula to be calculated is as follows Show:

$$
A T T_{t, t>T_{0}}=\frac{1}{N_{t r}} \sum_{i \in T}\left[T F P_{i t}(1)-T F P_{i t}(0)\right]=\frac{1}{N_{t r}} \sum_{i \in T} \delta_{i t}
$$

It should be noted that, like the synthetic control method, once the sample is given, the effect of implementing the FTZ policy $\delta_{i t}$ is fixed. The data after the implementation of the FTZ policy is what we can actually observe. The generalized synthetic control is to construct the counterfactuals to fit the corresponding data that will be derived from the assumption that the policy is not implemented in the region where the FTZ policy is implemented. .

Hypothesis 2: Strict exogenousness between factors

$$
\varepsilon_{i t} \perp D_{j s}, x_{j s}, \lambda_{j}, f_{s}, \forall i, j, t, s
$$

At any time, the random disturbance items are independent of the FTZ policy, the observed control variables and the unobserved variables between any enterprises is strict exogenousness.

Hypothesis 3: Weak sequence dependence of the error term. Assuming that weak correlation is allowed, but not strong sequence dependence, satisfying this assumption requires that the error term is not only independent of covariates, factors, and factor loads, but different companies should remain independent of each other at different times. It is also one of the assumptions of synthetic control.

Hypothesis 4: The data meets the regularity condition. This setting is to ensure that the estimator is moment convergent.

Hypothesis 5: The error terms are cross-section independent and covariance. This assumption is to ensure the validity of the inferred counterfactual data.

\section{Theoretical derivation of generalized synthetic control estimation method}

Generalized synthetic control is a prediction method based on the Bai (2009) factor enhancement model. The actual result of the implementation of the FTZ policy by enterprise $i$ at time $t$ is given by the difference between the observed value and the estimated counterfactual, namely $\hat{\delta}_{i t}=T F P_{i t}(1)-\widehat{T F P}_{i t}(0)$, among them $\widehat{T F P}_{i t}(0)$ is estimated in three steps.

Step 1: Use the control data to estimate the fixed-effect model and obtain $\widehat{\beta}, \hat{\mathrm{F}}, \hat{\Lambda}_{C O}$

$$
\left(\hat{\beta}, \hat{F}, \hat{\Lambda}_{C O}\right)=\underset{\tilde{\beta}, \tilde{F}, \tilde{\Lambda}_{C O}}{\arg \min } \sum_{i \in C}\left(T F P_{i}-X_{i} \tilde{\beta}-\tilde{F} \tilde{\lambda}\right)^{\prime}\left(T F P_{i}-X_{i} \tilde{\beta}-\tilde{F} \tilde{\lambda}\right)
$$

The constraints are: $\widetilde{\mathrm{F}}^{\prime} \tilde{\mathrm{F}}=I_{\mathrm{r}} \quad \hat{\Lambda}_{C O}^{\prime} \hat{\Lambda}_{C O}=$ diagonal

Step 2: Estimate the factor load of each enterprise by minimizing the mean square error of the predicted treatment results during pretreatment. 


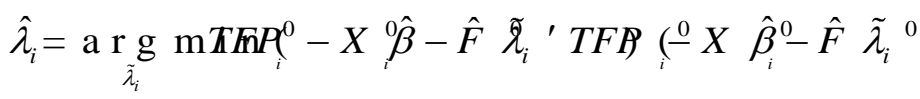

$$
\begin{aligned}
& \hat{\mathrm{F}}^{0}\left(\hat{\mathrm{F}}^{0-} \hat{\mathrm{F}}^{\prime}{ }^{0}{ }^{0} \boldsymbol{T F P}_{i}-{ }^{0} X_{i} \hat{\beta}^{0}\right)
\end{aligned}
$$

Among them $\hat{\beta}$ 和 $\hat{F}^{0}$ is from the first step's estimation result, the superscript " 0 " indicates the preprocessing time.

Step 3: Based on $\hat{\beta} 、 \hat{F}$ with $\widehat{\lambda}_{i}$, counting counterfactuals after processing

$$
T F P_{\mathrm{it}}(0)=X_{\mathrm{it}}^{\prime} \hat{\beta}+\hat{\lambda}_{i} \hat{\mathrm{f}}, \quad \mathrm{i} \in T, \mathrm{t}>\mathrm{T}_{0}
$$

Therefore, the increased TFP due to the establishment of a FTZ is:

$$
A T T=\left(1 / N_{t r}\right) \sum_{i \in T}\left[Y_{i t}(1)-Y_{i t}(0)\right], t>T_{0}
$$

The model estimates that when $t_{0}$ is very small, it will lead to inaccurate factor load estimation and cause accidental parameter problems, resulting in deviations in the estimation results, which is an important difference from the traditional fixed-effect model.

(2) Variable description and data source

In this paper, the TFP measured by the LP method is used as the explained variable. When using the LP method to measure TFP, it is a better plan to use the company's added value to estimate TFP. There are two methods to measure the added value: the production method and the distribution method. Whether the production method or the distribution method is based on financial data alone, it is not possible to calculate a more accurate value added. Benwei Hu (2014) uses corporate operating costs, three major expenses, depreciation of fixed assets, amortization of intangible assets , payment to employees and the cash paid for employees measure intermediate inputs, and uses operating income to measure total output. However, when this method is used in this paper, it is found that many added values are calculated as negative numbers. And Liya Liu et al. (2018) use depreciation, labor compensation, production tax, the net value and operating surplus to measure the added value. The difficulty of this method is that it is difficult to accurately measure the net production tax and operating surplus. Therefore, the benchmark analysis part of this paper uses Xiaodong Lu and Yujun Lian (2012) to measure the indicators used by TFP, using operating income to represent total output, the number of employees in the company to measure labor factors, fixed asset net worth to measure capital input, and the expenditure on purchasing goods and labor to measure intermediate input. Using the above indicators to measure tfp according to the LP method .

The data in this article are mainly from Wind and CSMAR databases, as well as the National Bureau of Statistics and China Economic Net. In order to avoid the problem of selective bias, this article selected the corporate financial data of A-share listed companies from 2004 to 2018. According to the CSRC and Wind's industry classification method, we categorizes enterprises by industry. These listed companies are generally larger in size, and the financial data are audited data, which is relatively more accurate. When selecting data, this article uses 2004 as a benchmark in order to obtain balanced panel data. In order to preventing the spillover effect, companies that are located in the provinces, cities and non-free trade zones where 11 free trade zones located are also eliminated. Finally, 569 companies are left every year. There are 213 companies in the free trade zone and 356 companies outside the free trade zone. There are 8535 samples in the 15-year sample data. In order to improving the comparability of the data, this article collect industrial producer prices and the index and fixed asset investment price index from China Economic Net and the National Bureau of Statistics.Referring to the processing methods of most articles, we deflated the operating income data using the industrial producer price index, and other financial data were deflated using the fixed asset investment price index. Chooseing 2000 as the base period. As shown in Table 2, this paper has made descriptive statistics on the main variables. In the table, TFP represents the TFP of the enterprise, $\operatorname{lnL}$ is the logarithm of the number of employees, roa is the rate of return on assets, and tdr represents the asset-liability ratio, currentratio is the current ratio.

Table 1. Descriptive statistics of variables

\begin{tabular}{c|c|c|c|c|c}
\hline variable & Mean & $\begin{array}{c}\text { Standard } \\
\text { deviation }\end{array}$ & Minimum value & Maximum & Observations \\
\hline$T F P$ & 11.743 & 1.083 & 7.897 & 16.217 & 8535 \\
\hline $\ln L$ & 7.920 & 1.362 & 2.303 & 13.020 & 8535 \\
\hline roa & 4.340 & 5.258 & -55.465 & 51.721 & 8535 \\
\hline$t d r$ & 0.497 & 0.185 & 0.023 & 0.964 & 8535 \\
\hline currentratio & 1.697 & 1.870 & 0.038 & 55.741 & 8535 \\
\hline
\end{tabular}

Source of data: sorted out after correcting based on wind data 


\section{Empirical Results and Analysis}

(1) Empirical results

As a major decision of the country, the FTZ is intended to further open up the Chinese economy, Chinese companies can make better use of international advanced technology, management experience and funds, and make overseas investment more convenient. Level and resource allocation efficiency promote the improvement of total factor productivity. The construction of FTZS can be used as a quasi-natural experiment, using the method of generalized synthetic control to evaluate the impact of FTZ construction on TFP.

This article uses software R and the gsynth package developed by Yiqing Xu (2017) to evaluate the policy effects of the establishment of 11 free trade zones on TFP. In the following analysis, companies in 11 regions that seting up a FTZ are used as the experimental group, while other regions are used as the control group. According to the third part, there are 213 companies in the experimental group and 356 companies in the control group. A fully balanced panel data with 15 years of data. The companies in the experimental group began to implement the FTZ policy in different years.

This paper analyzes these data using generalized synthetic control method.TFP as the explanatory variable, the free trade zone policy as the difference between the experimental group and the control group, the asset return rate and the asset-liability ratio as the two observable variables, and controls the annual and individual effects. Figure 2-1 and Figure 2-2 show the effect of the implementation of the free trade zone policy on tfp. Among them, the horizontal axis of Figure 2-1 and Figure 2-2 represents before and after the implementation of the FTZ policy. Implementation of the free trade zone policy, greater than 0 indicates that the existing area has implemented the free trade zone policy. The vertical axis of Figure 2-1 represents the effect of the implementation of the free trade zone policy. We can see from Figure 2-1 that the implementation of the free trade zone after the policy, the data gradually began to be greater than 0 and showed an upward trend, indicating that the FTZ policy can promote the TFP. In Figure 2-2, the vertical axis represents TFP, and the solid black line is an experiment's TFP calculated from the observation data, the blue dotted line is the TFP of the experimental group based on the fitting of the control group. It can be found that before the implementation of the FTZ policy, the two curves almost completely overlap, and the data of the control group can fit the experiment better. After the implementation of the policy, the solid black line is gradually higher than the blue dashed line, proving that the free trade zone policy can indeed improve the tfp of the enterprise.

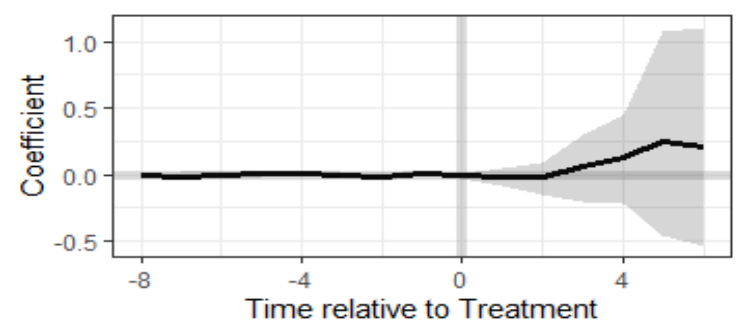

Figure 2.1.The effect of FTZ on TFP

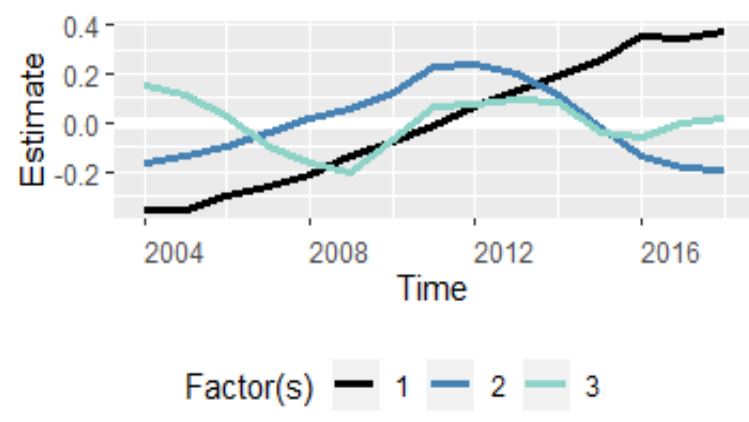

Figure 3.1. Potential impact factors

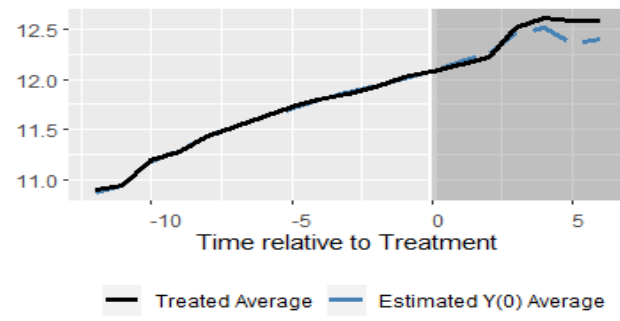

Figure 2.2. The real and fitted values

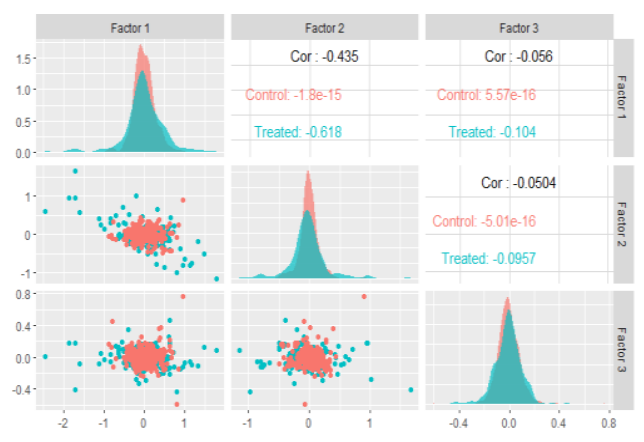

Figure 3.2. Factor loading

The corresponding potential impact factors and factor loads are listed in Figure 3-1 and Figure 3-2, respectively. Generalized synthetic control is based on the estimation of potential impact factors and factor loads, so that the experimental group data can be better perform fitting. 


\section{(2) Robustness test}

In order to ensure the validity of the analysis results and verify that the FTZ policy can indeed promote the TFP of the enterprise, this article refers to Thorsten Beck et al. (2010) multi-period DID ideas, conducted an empirical investigation on whether the FTZ construction promotes the growth of TFP . Enterprises of 11 provinces and cities where the FTZ is located as the experimental group, and the enterprises of other provinces and cities as the control group. Useing the time of the establishment of the FTZ as a cut-off point, and dividing the 2004-2018 samples into four parts: enterprises in provinces and cities that established FTZS, enterprises in provinces and cities that have not established FTZS, enterprises in provinces and cities before the establishment of FTZS, and enterprises in provinces and cities after the establishment of FTZS. Time as a dummy variable of whether the FTZ is established or not , Group as a virtual variable whether to establish a FTZ. These two sets of dummy variables are represented by 0 and 1 . The specific measurement model is constructed as follows

$$
T F P_{\mathrm{it}}=\alpha_{0}+\alpha_{1} \text { Time } \times G \operatorname{roup}+\sum_{\mathrm{i}=1}^{N} \beta X_{\mathrm{it}}+\mu_{\mathrm{it}}+v_{\mathrm{it}}+\varepsilon_{\mathrm{it}}
$$

In the above formula, $i$ represents the province, $t$ represents the year, TFP is the explanatory variable, which represents the total factor productivity of each enterprise, and X represents a set of control variables, including the age of the enterprise, the nature of the owner of the enterprise, the net interest rate of sales, the net interest rate of total assets, Variables such as asset-liability ratio and current ratio. Time is a dummy variable, and the value is 1 after the establishment of the FTZ and 0 before the establishment of the FTZ. Group is a dummy variable whether the enterprise is in the free trade zone. The value in the FTZ is 1 , and the value not in the FTZ is 0 . Time $\times$ Group is a double difference term, its coefficient $\alpha_{1}$ is the most concerned variable, this coefficient reflects the effect of FTA policy on TFP.

\section{Parallel trend test}

Investigating FTZ policies using the double difference method needs to meet parallel trends. If the implementation time of the FTZ is a single point in time, for example, all free trade zones are implemented in 2013, then you can use the graph to observe Whether the experimental group and the control group met the parallel trend before the establishment of the FTZ. However, the establishment time of different FTZs is not the same time point.The parallel trend test is carried out.Refer Thorsten Beck et al. (2010), using the counterfactual method to put the time of all FTZS is advanced or delayed at the same time, to see whether the FTZ policy has increased the TFP significantly. If the early implementation of the FTZ policy has no significant effect on the TFP, but the delayed implementation of the policy has significant effect on the TFP. It is considered that the FTZ policy is in line with the parallel trend before implementation. The equation for the parallel trend test of this method is as follows:

$$
T F P_{\mathrm{it}}=\beta_{0}+\beta_{1} \mathrm{D}_{i t}^{-10}+\beta_{2} \mathrm{D}_{i t}^{-9}+\ldots .+\beta_{15} \mathrm{D}_{i t}^{+5}+\sum_{\mathrm{i}=1}^{N} \eta X_{\mathrm{it}}+\mu_{\mathrm{it}}+v_{\mathrm{it}}+\varepsilon_{\mathrm{it}}
$$

Among them,TFP $i t$ represents the TFP of the enterprise $\mathrm{i}$ in the $\mathrm{t}$-th year, D represents the dummy variable of time, and $D^{-10}$ to $D^{+5}$ represents the number of periods of policy advance or lag. The reason for choosing 10 periods ahead and 5 periods behind is because the data used is 2004-2018. The earliest established the Shanghai FTZ is 2013, which can be pushed forward by 9 periods and backward by 5 periods. However, as of 2018, there are still many provinces that have not implemented the FTZ policy. All enterprises that have not implemented the free trade zone policy have been placed in the ten-phase advance period.

Figure 4 shows the parallel trend test of the multi-period did. Using a 95\% confidence interval, we observe the trend of the change in the control variable $\beta$. According to the results, we found that the $\beta$ coefficient did not pass the significance level test in 2004-2014, and passed the significance level test in 2015-2018. It shows that since the establishment of the Shanghai FTZ 2013, the policy has shown significant effects since 2015, which also shows that the experimental group and the control group meet the parallel trend hypothesis before implementing the policy. 


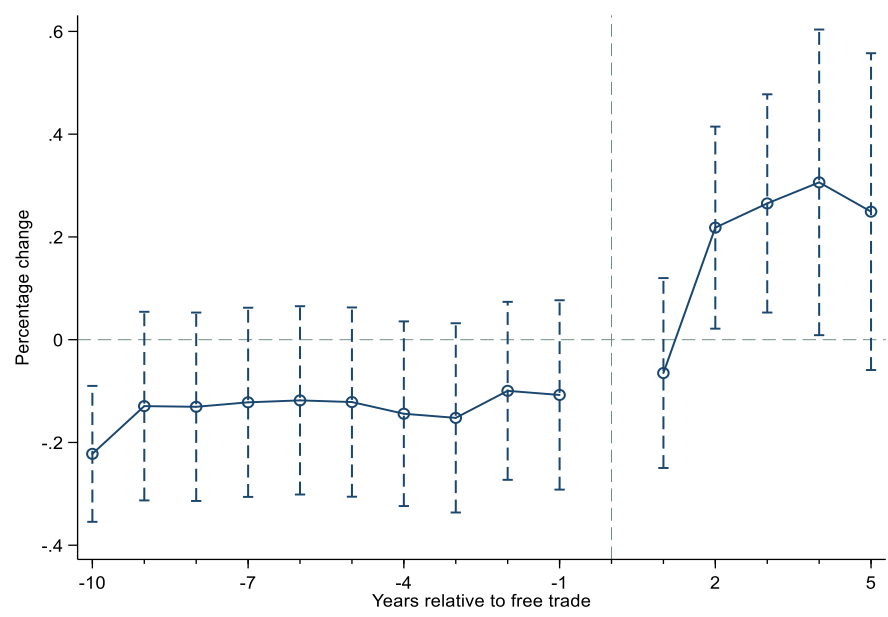

Figure 4. Parallel trend test

\section{Benchmark regression of FTZS construction to TFP}

Table 2 reports the benchmark regression model of the multi-period did, which useing the TFP measured by the Lp method as the explanatory variable, and whether the FTZ is set up as the core explanatory variable at a specific time. Model 1 and model 2 do not control time and industry effects; Model 3 and Model 4 are benchmark regression models that control the effect of time and industry. Comparing (2) and (4) in Table 2,we can be found that time and industry have a great impact on TFP. Controlling the industry and time, the FTZ's interpretation factor for TFP becomes smaller. This should be in line with our economic intuition, from 2004 to 2018, regardless of whether the enterprise is in the FTZ or not, the production technology and the management level of the surviving enterprise must be great development. This article focuses on the effect of FTZ policie. After controlling the time and industry factors, FTZ policie still has a significant positive impact on tTFP, proving that free trade zone policies can promote The development of TFP.

Table 2. Benchmark regression model

\begin{tabular}{|c|c|c|c|c|}
\hline & (1) & (2) & (3) & (4) \\
\hline Time $\times$ Group & $\begin{array}{l}0.604^{* * * *} \\
(0.022)\end{array}$ & $\begin{array}{l}0.427^{* * * *} \\
(0.029)\end{array}$ & $\begin{array}{c}0.259^{* * * *} \\
(0.072)\end{array}$ & $\begin{array}{l}0.148^{* * * *} \\
(0.049)\end{array}$ \\
\hline Owner & - & $\begin{array}{l}0.142^{* * * * * * 6} \\
(0.020)\end{array}$ & - & $\begin{array}{l}0.162^{\text {**** }} \\
(0.064)\end{array}$ \\
\hline $\ln L$ & - & $\begin{array}{l}0.370^{6 * 6 *} \\
(0.007)\end{array}$ & - & $\begin{array}{l}0.328 \\
(0.046)\end{array}$ \\
\hline $\mathrm{tdr}$ & - & $\begin{array}{l}1.483^{* * * * *} \\
(0.058)\end{array}$ & - & $\begin{array}{l}1.447^{* * * * 4} \\
(0.335)\end{array}$ \\
\hline curentratio & - & $\begin{array}{l}0.029^{* * * * *} \\
(0.005)\end{array}$ & - & $\begin{array}{l}0.017^{* * * * 4} \\
(0.016)\end{array}$ \\
\hline Cons & 11.688 & 7.745 & 11.120 & 7.900 \\
\hline Industry fixed & $\mathrm{N}$ & $\mathrm{N}$ & $\mathrm{Y}$ & $\mathrm{Y}$ \\
\hline Fixed time & $\mathrm{N}$ & $\mathrm{N}$ & $\mathrm{Y}$ & $\mathrm{Y}$ \\
\hline Within $-R^{2}$ & 0.083 & 0.379 & 0.140 & 0.421 \\
\hline Observations & 8535 & 8535 & 8535 & 8535 \\
\hline
\end{tabular}

Note: () is the firm standard error at the enterprise level, ${ }^{* * *},{ }^{* * *},{ }^{*}$ are significant at the levels of $1 \%, 5 \%$, and $10 \%$, respectively.

\section{Analysis of Influence Mechanism}

How does FTZ policy affect TFP? Based on the analysis of the theoretical mechanism in Part III, this article has empirically tested the innovation-driven effects and adjustment effect of resource allocation.

(I) Innovation driving effect

Innovation is an important factor to promote the increase of TFP. In this paper, the company's technological innovation is used as an intermediary variable to promote the growth of TFP in the FTZ. The study of this variable is based on the knowledge that the free trade zone promotes the growth of total factor productivity. To explore the internal mechanism 
between the FTZ and TFP. This article uses the annual patent number of listed companies announced by the State Intellectual Property Office as a proxy variable to measure the level of enterprise technological innovation.

According to the systematic introduction of intermediary effects by Jing Tan and Jianhua Zhang (2018), the steps constructing intermediary effects are: (1) Review the total factor productivity of the FTZ. If the coefficient is significantly positive, it means that the construction of the FTZ can promote TFP; (2) The FTZ regresses the annual number of patents of the enterprises. If the coefficient is significantly positive, it means that the construction of the FTZ is conducive to the improvement of the company's innovation level; (3) The number of patents is used to explain the increase in the enterprise's TFP. If the coefficient is significantly positive, it means that technological innovation can promote the increase of TFP; (4) Using the FTZ policy and industrial structure to heighten the interpretation of TFP at the same time, to see whether the coefficient is significant. As mentioned above, construct an intermediary effect model:

$$
\begin{gathered}
\operatorname{TFP}_{i t}=\alpha_{0}+\alpha_{1} T \times G+\alpha_{2} \text { owner }_{i t}+\alpha_{3} \text { tdr }_{i t}+\alpha_{4} \text { currentratio }_{i t}+\varepsilon_{i t} \\
\operatorname{lnPatent}_{i t}=\beta_{0}+\beta_{1} T \times G+\beta_{2} \text { owner }_{i t}+\beta_{3} \text { tdr }_{i t}+\beta_{4} \text { currentratio }_{i t}+\gamma_{i t} \\
\operatorname{TFP}_{i t}=\chi_{0}+\chi_{1} \text { lnPatent }_{i t}+\chi_{2} \text { owner }_{i t}+\chi_{3} \text { tdr }_{i t}+\chi_{5} \text { currentratio }_{i t}+\xi_{i t} \\
\mathrm{TFP}_{i t}=\delta_{0}+\delta_{1} \text { lnPatent }_{i t}+\delta_{2} T \times G+\delta_{3} \text { owner }_{i t}+\delta_{4} \text { tdr }_{i t}+\delta_{6} \text { currentratio }_{i t}+v_{i t}
\end{gathered}
$$

Among them, TFP is total factor productivity, TXG represents the policy variables for the construction of the FTZ; Inpatent is the number of patents authorized by the enterprise that year. Due to the availability of data, this article only obtained the patent data from 2004-2017 from the CSMAR database.The owner represents the nature of the enterprise owner, which is a dummy Variables, 1 represents state-owned enterprises, 0 represents non-state-owned enterprises. Enterprises missing patent data are deleted, and the innovation-driven effect is tested using unbalanced panel data from 2004 to 2017.

Table 3. Innovation-driven mediation effects

\begin{tabular}{c|c|c|c|c}
\hline variable & $(1)$ & $(2)$ & $(3)$ & $(4)$ \\
\hline \multirow{2}{*}{$T \times G$} & $0.300^{* * *}$ & $0.232^{* *}$ & $(0.026)$ \\
\hline \multirow{2}{*}{ InPatent } & $(0.080)$ & $(0.121)$ & $0.251^{* * *}$ & $0.242^{* * *}$ \\
& - & - & $(0.027))$ & $(0.082)$ \\
\hline Owner & $0.205^{* * *}$ & 0.079 & $0.189^{* * *}$ & $0.185^{* * *}$ \\
\hline tdr & $(0.081)$ & $(0.100)$ & $(0.077)$ & $(0.077)$ \\
\hline currentratio & $2.215^{* * *}$ & $0.769^{*}$ & $2.026^{* * *}$ & $(0.300)$ \\
\hline Cons_- & $(0.322)$ & $(0.100)$ & $(0.298)$ & 0.019 \\
\hline Within-R & 0.012 & -0.025 & 0.018 & $(0.019)$ \\
\hline Industry fixed & $(0.019)$ & $(0.018)$ & $(0.018)$ & 9.196 \\
\hline Annual fixed & 9.516 & 1.285 & 9.189 & 0.365 \\
\hline Observations & 0.263 & 0.210 & 0.361 & $\mathrm{Y}$ \\
\hline
\end{tabular}

Note: 1 . The () is the firm standard error at the enterprise level, ${ }^{* * *},{ }^{* * *},{ }^{*}$ are significant at the levels of $1 \%, 5 \%$, and $10 \%$, respectively.

2. Regression in columns (1)-(4) represents panel regression for equations (14)-(17), respectively.

Table 3 shows that after controlling the industry and the annual effect, the establishment of the FTZ can promote enterprise innovation, and innovation has a significant impact on the improvement of tfp. It can be seen that patents play 
an intermediary role in the construction of the FTZ and the improvement of TFP. The construction of the FTZ promotes the improvement of TFP by promoting enterprise innovation.

(II) Adjustment effect of resource allocation

The establishment of a FTZ promotes enterprise TFP by improving the efficiency of resource allocation. In this paper, the rate of return on assets is used as a regulatory variable to test the resource allocation effect of the FTZ. The specific measurement model is as follows:

$$
\operatorname{TFP}_{i t}=\varphi_{0}+\varphi_{1} T \times G \times \operatorname{roa}_{i t}+\varphi_{2} \text { owner }_{i t}+\varphi_{3} \ln L_{i t}+\varphi_{4} t_{d r}+\varphi_{5} \text { currentratio }_{i t}+\vartheta_{i t}
$$

In the above formula, roa represents the return on assets, and the data comes from the wind database. If the regression coefficient of $T \times G \times$ roa $_{i t}$ is a positive value, which means that the establishment of a FTZ can affect TFP through the return on assets.

Table 4 verifies the resource allocation effect of FTZ construction. Models (1) and (2) do not consider time and industry fixed effects, and models (3) and (4) add time and industry fixed effects. From the table we can know $T \times G \times$ roa in the model (1)-(4) passed the significance test at the $1 \%$ level.

In summary, regardless of whether you join the industry and the time fixed effect, the asset return rate and the construction of the FTZ can work together to promote the growth of TFP.The asset return rate can play a important role in resource regulation. When the asset return rate is higher, the FTZ has a greater impact on TFP, this conclusion confirms the resource allocation effect hypothesis.

Table 4. Moderating effects of resource allocation

\begin{tabular}{|c|c|c|c|c|}
\hline & (1) & (2) & (3) & (4) \\
\hline$T \times G \times$ roa & $\begin{array}{l}0.057^{* * *} \\
(0.003)\end{array}$ & $\begin{array}{c}0.051^{* * *} \\
(0.004)\end{array}$ & $\begin{array}{l}0.031^{* * *} \\
(0.008)\end{array}$ & $\begin{array}{l}0.030^{* * * *} \\
(0.007)\end{array}$ \\
\hline owner & - & 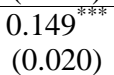 & - & $\begin{array}{c}0.165^{* * *} \\
(0.064)\end{array}$ \\
\hline $\ln L$ & - & $\begin{array}{c}0.373^{\text {******* }} \\
(0.007)\end{array}$ & - & $\begin{array}{l}0.326^{* * * *} \\
(0.046)\end{array}$ \\
\hline$t d r$ & - & $\begin{array}{l}1.537^{\text {***** }} \\
(0.058)\end{array}$ & - & $\begin{array}{l}1.480^{* * * *} \\
(0.338)\end{array}$ \\
\hline currentratio & - & 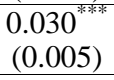 & - & $\begin{array}{c}0.017 \\
(0.016) \\
\end{array}$ \\
\hline Cons_ & 11.721 & 7.705 & 11.120 & 7.897 \\
\hline Industry fixed & $\mathrm{N}$ & $\mathrm{N}$ & $\mathrm{Y}$ & $\mathrm{Y}$ \\
\hline Annual fixed & $\mathrm{N}$ & $\mathrm{N}$ & $\mathrm{Y}$ & $\mathrm{Y}$ \\
\hline Within- $R^{2}$ & 0.042 & 0.376 & 0.140 & 0.423 \\
\hline Observations & 8535 & 8535 & 8535 & 8535 \\
\hline
\end{tabular}

Note: 1 . The firm standard errors in parentheses are in parentheses, ${ }^{* * *},{ }^{* * *},{ }^{*}$ are significant at the levels of $1 \%, 5 \%$, and $10 \%$, respectively.

\section{Heterogeneity Analysis of TFP in the Construction of FTZ}

(1) Heterogeneity analysis of enterprise nature

Although this article has discussed that the FTZ has a positive impact on TFP. Is there a certain difference in the impact of the pilot scope on enterprises of different nature? Discussing this issue can help to understand the FTZ construction on TFP. This paper divides enterprises into state-owned enterprises and non-state-owned enterprises according to the nature of enterprises, and discusses the impact of FTZ construction on TFP from the perspective of the nature of enterprises.

Table 5. The impact of different types of enterprises on TFP 


\begin{tabular}{|c|c|c|c|c|}
\hline \multirow{2}{*}{ variable } & \multicolumn{2}{|l|}{ OLS } & \multicolumn{2}{|l|}{ FE } \\
\hline & (1) Non-state-owned & (2) State-owned & (3) Non-state-owned & (4) State-owned \\
\hline$T \times G$ & $\begin{array}{l}0.047 \\
(0.087)\end{array}$ & $\begin{array}{l}0.234^{* *} \\
(0.096)\end{array}$ & $\begin{array}{r}-0.016 \\
(0.062)\end{array}$ & $\begin{array}{r}0.160^{* *} \\
(0.070)\end{array}$ \\
\hline $\ln L$ & $\begin{array}{r}0.220^{* * * *} \\
(0.054)\end{array}$ & $\begin{array}{l}0.266^{* * *} \\
(0.067)\end{array}$ & $\begin{array}{r}0.265^{* * * *} \\
(0.052)\end{array}$ & $\begin{array}{r}0.295^{* * * *} \\
(0.056)\end{array}$ \\
\hline roa & $\begin{array}{r}0.054^{* * *} \\
(0.008)\end{array}$ & $\begin{array}{l}0.052^{* * * *} \\
(0.006)\end{array}$ & $\begin{array}{r}0.049^{* * *} \\
(0.007)\end{array}$ & $\begin{array}{r}0.051^{* * * *} \\
(0.005)\end{array}$ \\
\hline$t d r$ & $\begin{array}{r}2.967^{* * *} \\
(0.468)\end{array}$ & $\begin{array}{l}2.673^{* * *} \\
(0.368)\end{array}$ & $\begin{array}{r}2.351^{* * *} \\
(0.510)\end{array}$ & $\begin{array}{r}1.802^{* * *} \\
(0.289)\end{array}$ \\
\hline currentratio & $\begin{array}{l}0.043 \\
(0.034)\end{array}$ & $\begin{array}{l}0.038^{*} \\
(0.024)\end{array}$ & $\begin{array}{l}0.032 \\
(0.025)\end{array}$ & $\begin{array}{l}-0.003 \\
(0.014)\end{array}$ \\
\hline Cons_ & 7.754 & 7.664 & 7.754 & 7.924 \\
\hline Industry fixed & $\mathrm{Y}$ & $\mathrm{Y}$ & $\mathrm{Y}$ & $\mathrm{Y}$ \\
\hline Annual fixed & $\mathrm{Y}$ & $\mathrm{Y}$ & $\mathrm{Y}$ & $\mathrm{Y}$ \\
\hline Within $-R^{2}$ & 0.472 & 0.446 & 0.469 & 0.473 \\
\hline Observations & 2760 & 5775 & 2760 & 5775 \\
\hline
\end{tabular}

Note: () is the firm standard error at the enterprise level, ${ }^{* * *},{ }^{* *},{ }^{*}$ are significant at the levels of $1 \%, 5 \%$, and $10 \%$, respectively.

Table 5 is a report of its results. It can be found that whether it is ols regression or fixed effect regression, the effect of non-state-owned enterprises in the FTZ on TFP is not significant, while the effect of state-owned enterprises on tfp is passed 5\% significant test. From this table, it is judged that the FTZ policy mainly promotes the improvement of TFP by affecting state-owned enterprises.

Based on the above heterogeneity analysis, we explore the reasons that: (1) The construction of FTZS promotes the improvement of TFP through innovation-driven effects. Generally speaking, state-owned enterprises have more abundant funds to support R\&D investment, and in Chinese state-owned enterprises are more likely to attract senior talents. After the implementation of the FTZ policy, state-owned enterprises are better able to seize the opportunity to improve TFP. (2) The construction of FTZS can affect TFP through the effect of resource allocation. State-owned enterprises are generally larger than non-state-owned enterprises. The rate of return on assets in state-owned enterprises has increased significantly after the establishment of FTZ, and the TFP has been promoted through the resource allocation effect.

In summary, state-owned enterprises have relatively few constraints and are more efficient in promoting innovation and resource allocation. As a result, the establishment of free trade zones in China has a strong explanation for the promotion of TFP.

(2) Heterogeneity analysis of the FTZ

The fourth part of this article has proved that the free trade zone can promote the growth of tfp. But is there any heterogeneity in the promotion effect of 11 free trade zones on tfp? This part uses the general synthetic control to analysis tfp of 11 free trade zones. For specific results, see Figure 5 to Figure 15.
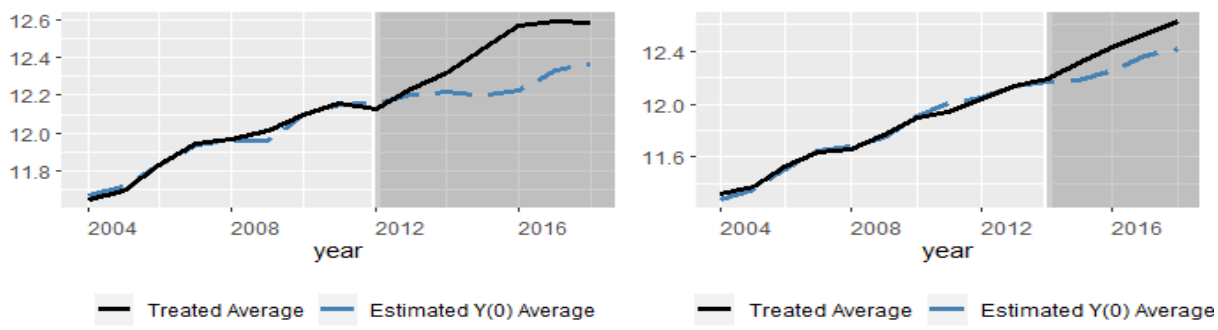

Figure 5. Shanghai FTZ impact on TFP

Figure 6. Guangdong FTZ impact on TFP 


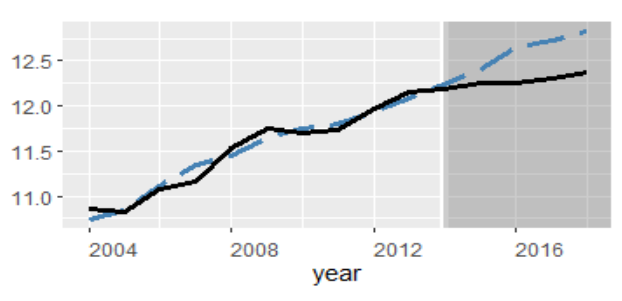

- Treated Average - Estimated $Y(0)$ Average

Figure 7. Tianjin FTZ impact on TFP

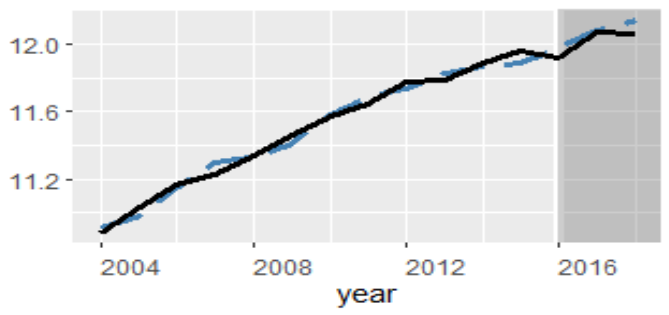

- Treated Average — Estimated Y(0) Average

Figure 9. Henan FTZ impact on TFP

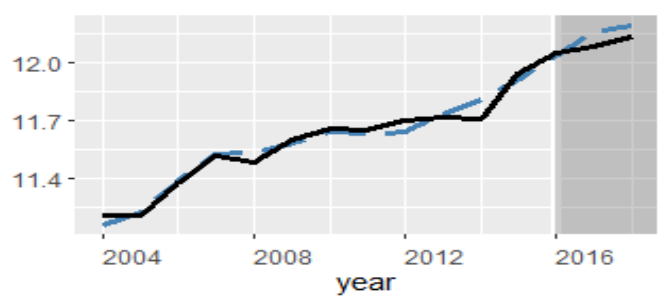

- Treated Average - Estimated Y(0) Average

Figure 11. LiaoningFTZ impact on TFP

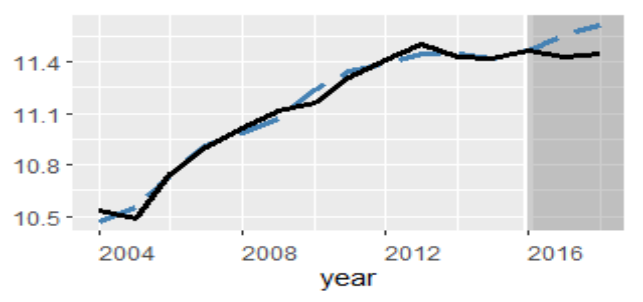

- Treated Average — Estimated $Y(0)$ Average

Figure 13. Sichuan FTZ impact on TFP

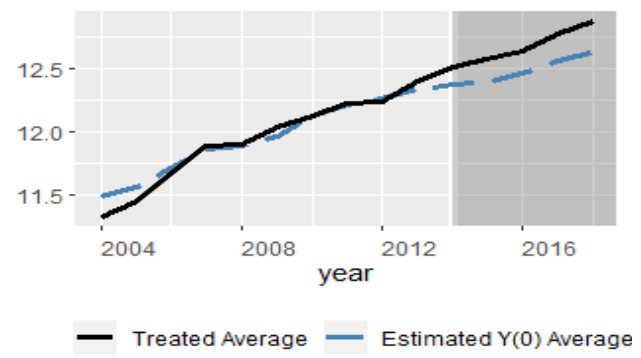

Figure 8. Fujian FTZ impact on TFP

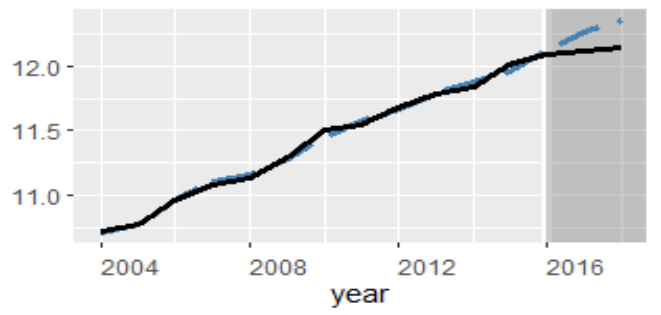

- Treated Average — Estimated Y(0) Average

Figure 10. Hubei FTZ impact on tfp

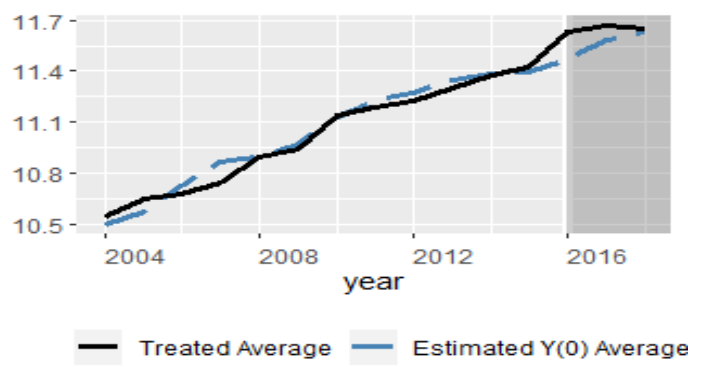

Figure 12. Shaanxi FTZ impact on TFP

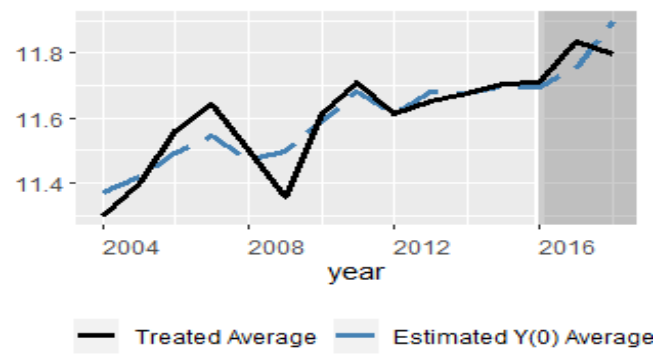

Figure 14. Zhejiang FTZ impact on tfp

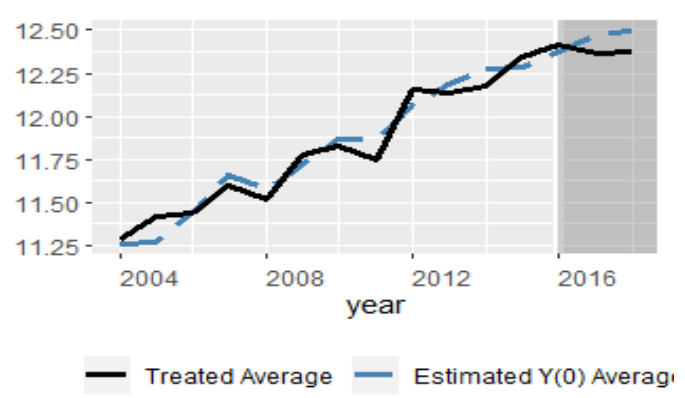


Figure 15. Chongqing FTZ impact on tfp

We can find that the establishment of the Shanghai FTZ is the earliest, and the promotion effect on tfp is also the most obvious. Among the second batch of free trade zones, the real values of Guangdong and Fujian FTZS are greater than the fitted values, indicating that the FTZ policies have promoted TFP. But Tianjin Free Trade Zone has shown the opposite result, the enterprises selected by Tianjin in this article are mainly in Binhai New Area, and the explosion accident in Tianjin Binhai New Area in August 2015 is likely to affect the normal development of enterprises. Although the establishment of a free trade zone, the promotion of tfp has a certain time lag. The fact that the fitted value of the tfp data in Tianjin is greater than the true value is most likely due to the explosion in the Tianjin Binhai New Area. For the third batch of newly established FTZS, the study found that only Shaanxi had a true value greater than the fitted value. The construction of the FTZ plays a positive role in the growth of tfp, but the effect of the other six newly established FTZS is not significant, which is likely to be affected by the following reasons: (1) According to the fourth part of the robustness test parallel trend analysis, the construction of FTZ promotes TFP growth itself has a certain time lag, and the establishment of the new FTZ is relatively short; the role of the free trade zone has not yet been fully reflected. (2) In 2018, the Sino-U.S. trade friction intensified. It has a greater impact and has a greater impact on the enterprises in the experimental group.There is a reverse impact on the policy of the FTZ. (3) The country approved the establishment of a free trade zone, each free trade zone has its own tasks, and the impacts it receives will also be different. Causing the 7 newly established free trade zones to exhibit heterogeneity when they are exposed to external shocks in the short term. In the long run, the FTZ policy can promote the improvement of TFP.

\section{Conclusion and Policy Implications}

(I) Research conclusion

After the financial crisis in 2008, China gradually entered the new normal of economic growth. In order to achieve high-quality economic development, China has proposed policies and guidelines for supply-side structural reform and further expansion of opening up. The construction of the FTZ is to further expand Opening up and improving the competitiveness of Chinese enterprises. TFP is an important indicator to measure the development status of enterprises. This article is based on the enterprise-level panel data of Chinese a-share listed companies from 2004 to 2018, and adopts the generalized synthetic control method and the multi-period did method to analysis whether the establishment of FTZS promote enterprise's TFP. The results are as follows:

(1) The effect of the policy evaluation of the generalized synthetic control method and the multi-phase did shows that after controlling the fixed effect, the effect of the construction of the FTZ on TFP is significantly positive, indicating that the establishment of the FTZ has significantly improved the enterprise TFP.

(2) The construction of a FTZ can promote the development of TFP through the innovation-driven effect and resource allocation effect. This paper uses the patent data obtained by the company as an agency variable for innovation. Innovation drive has a significant intermediary effect, and the construction of a FTZ can promote innovation level, and then improve the enterprise TFP. Using asset return as a proxy variable for resource allocation, through the adjustment effect of resource allocation, the FTZ has a significant role in promoting the improvement of TFP.

(3) This paper also analyzes the heterogeneity of enterprises and regions, and divides enterprises into state-owned enterprises and non-state-owned enterprises. It is believed that in the process of FTZ construction, state-owned enterprises have a significant effect in promoting the growth of TFP. When analyzing the region's knownness, eleven FTZS are separately analyzed using the generalized synthetic control method, and the areas where the FTZ was established early have the most obvious promotion effect on TFP.

(II) Policy inspiration

This paper holds that promoting trade liberalization and building high-quality FTZ plays an important role in improving the TFP of enterprises. According to the conclusion, this paper puts forward the following three suggestions for the construction of the FTZ.

(1) Technological innovation plays an important role in the construction of FTZ and the improvement of TFP. The construction of the FTZ needs to build a good business environment and improve the ability of the FTZ to attract technology and talents. First, we should make full use of the various preferential policies of the FTZ to stimulate the innovative vitality of the main body of enterprises. Enterprises can participate fully in the international market competition, research and development and learning advanced technology and management capabilities;

(2) The allocation of resources plays a regulating effect between the FTZ and the TFP. To play the role of FTZ on total factor productivity, it is necessary to improve the efficiency of resource allocation. First, the FTZ should make use of the role of the market itself, using the invisible hand to improve the efficiency of enterprise resource allocation.FTZ 
should also play the role of government intervention, using negative list policy to prevent foreign-invested enterprises that are not conducive to the long-term high-quality development of the FTZ;

(3) Paying attention to the role played the enterprise heterogeneity in promoting TFP in the FTZ. Firstly, according to the nature of enterprises, state-owned enterprises should play their own financing advantages, attract high-level talents from all over the world, and pay attention to scientific and technological innovation; Secondly, the industry and region of the FTZ enterprises are heterogeneous. The enterprises of the FTZ should seek the road of increasing productivity according to their region and industry, but not imitation.According to the actual situation, we promote TFP by using the FTZ.

\section{References}

Abadie, A. (2005). Semiparametric Difference-in-Differences Estimators. [J]. The Review of Economic Studies, 72(1), 1-19. https://doi.org/10.1111/0034-6527.00321

Abadie, A., Alexis, D., \& Jens, H. (2010). Synthetic Control Methodsfor Comparative Case Studies: Estimating the Effect of California's Tobacco Control Program. [J]. Journal of the American Statistical Association, 105(490), 493-505. https://doi.org/10.1198/jasa.2009.ap08746

Bai, J. S. (2003). Theory for Factor Models of Large Dimensions[J]. Econometrica, 71(1), 135-137. https://doi.org/10.1111/1468-0262.00392

Bai, J. S. (2009). Panel Data Models with Interactive Fixed Effects[J]. Econometrica, 77, 1229-1279. https://doi.org/10.3982/ECTA6135

Bi, Y. J., Tang, H. Y., \& Yin, D. S. (2014). Restrictive factors and countermeasures faced by the transformation of Shanghai Free Trade Zone [J]. Economic Aspect, 2014(8), 8-12.

Bin, S. (2017). Evaluation and Prospect of China Free Trade Pilot Zone [J]. International Trade, 2017(6), 7-13.

Chen, A. Z., \& liu, Z. B. (2014). Free Trade Zone: China's Open Economy "Second Season" [J]. Academic Monthly, 2014(1), 20-28.

Chen, Q., \& Liu, W. (2014). Motivations and economic effects of establishing China (Shanghai) Pilot Free Trade Zone [J]. Science Development, 2014(2), 43-50.

Chen, S. H., Tao, L. Y., \& Huang, J. (2014). Research on the development of service trade in the context of Shanghai Free Trade Zone [M]. Fudan University Press, First Edition, May 2014.

Ding, Y. B., Fu, Y. J., \& Cao, Y. (2014). Financial development, technological innovation and industrial structure optimization-Based on the empirical analysis of middle-income countries [J]. Industrial Economic Review, 2014(1), 82-99.

Expert Group of Shanghai University of International Business and Economics. China (Shanghai) Pilot Free Trade Zone and International Economic Cooperation [M]. Shanghai University of Finance and Economics Press, first edition in December 2013.

Han, R. D., \& Bo, B. (2019). Research on the Impact of Free Trade Pilot Zone on Capital Flows-Based on the Perspective of Quasi-Natural Experiments [J]. Financial Research.

$\mathrm{Hu}, \mathrm{B} . \mathrm{W}$. (2014). Financing constraints of Chinese manufacturing listed companies [D]. Master thesis of Nanjing University.

Levinsohn, J., \& Petrin, A. (2003). Estimating Production Functions Using Inputs to Control for Unobservables [J]. Review of Economic studies, 70(2), 317-341. https://doi.org/10.1111/1467-937X.00246

Liu, B. S., \& Cheng L. V. (2017). Difference analysis of the effect of free trade zone on regional economy-Comparative research based on synthetic control method [J]. International Trade Issues, 2018(3), 51-66.

Liu, B. S., \& Wang, Y. (2018). Research on the effect of free trade zone on regional innovation ability-Evidence from the quasi-experiment of Shanghai Free Trade Pilot Zone [J]. Economics and Management Research, 2018(9), 65-74.

Liu, Q. Y., \& Liu . Z. L. (2017). Research on the role of informatization in promoting the upgrading of the publishing industry [J]. China Publishing, 2017(21), 63-65.

Lu, X. D., Lian, Y. J. (2012). Estimation of total factor productivity of Chinese industrial enterprises: 1999-2007[J]. Economics (Quarterly), 2012(2), 541-558.

Massimo, D. G., Adrianna, D. L., \& Petraglia, C. (2008). Measuring Productivity [J]. Working paper CRENoS 2008.

Neyman, J. (1923). On the Application of Probability Theory to Agricultural Experiments: Essay on Principles [J]. Statistical Science, 5, 465-80. Section 9 (translated in 1990). https://doi.org/10.1214/ss/1177012031

Rubin, D. B. (1974). Estimating Causal Effects of Treatments n Randomized and nonrandomized Studies [J]. Journal of Educational Psychology, 5(66), 688-701. https://doi.org/10.1214/ss/1177012031

Tan, N., Zhou, X. B., \& Lin, J. H. (2015). Research on the Economic Growth Effect of Shanghai Free Trade Zone-Counterfactual Analysis Method Based on Panel Data [J] International Trade Issues, 2015(10), 14-24. 
Thorsten, B., Ross, L., \& Alexey, L. (2010). Big Bad Banks? The winners and Losers from Bank Deregulation in the United States[J]. The Journal of Finance, 65(5), 1637-1667. https://doi.org/10.1111/j.1540-6261.2010.01589.x

Wang, L. H., \& Liu, Z. H. (2017). Research on the effect of Shanghai Free Trade Zone on the regional economy [J]. International Trade Issues, 2017(2), 3-15.

Xiang, H. J., \& He, K. (2016). The influence of free trade zones and capital flows: a natural experimental study with Shanghai as an example [J]. International Trade Issues, 2016(8), 3-15.

Xie, Q. L., Roski, \& Zhang. Y. F. (2008). Growth and convergence of China's industrial productivity [J]. Economics (Quarterly), 2008(3), 809-826.

Xu, Y. Q. (2017). Generalized Synthetic Control Method: Causal Inference with Interactive Fixed Effects Models[J]. Political Analysis, 25(1), 57-76. https://doi.org/10.1017/pan.2016.2

Yang, X. D. (2014). A preliminary study on the relationship between economic and political effects in China (Shanghai) Pilot Free Trade Zone [J]. Journal of Shanghai University of Finance and Economics, 2014(6), 97-104.

Zhang, J., Li, Y., \& Liu, Z. B. (2009). Does Export Promote the Increase of Productivity of Chinese Enterprises?-Evidence from Chinese Local Manufacturing Enterprises[J]. Management World, 2009(12), 11-26.

Zhang, Y. W. (2014). Free Trade Zone Experiment and Open Economic System Construction [J]. Academic Monthly. 2014(4), 11-19.

Zhou, C. (2020). Whether the Construction of the Free Trade Zone Will Help Improve the Total Factor Productivity of Enterprises-Evidence from Chinese A-Share Listed Companies. International Business Research, 13(3), 15-26. https://doi.org/10.5539/ibr.v13n3p15

Zhuo, C. F., \& Deng, F. (2018). Inter-regional flow of innovation elements and upgrading of industrial structure [J]. Exploration of economic issues, 2018(5), 70-79.

\section{Copyrights}

Copyright for this article is retained by the author(s), with first publication rights granted to the journal.

This is an open-access article distributed under the terms and conditions of the Creative Commons Attribution license which permits unrestricted use, distribution, and reproduction in any medium, provided the original work is properly cited. 